УДК 343.341 .1

М.С. Кармановский

кандидат юридических наук

Алтайский институт экономики - филиал частного образовательного учреждения высшего образования "Санкт-Петербургский университет технологий управления и экономики» Российская Федерация, 656011, Алтайский край, г. Барнаул, пр. Ленина, 106-е

ORCID: 0000-0001-8918-8334.E-mail: gertelev@yandex.ru

\title{
Е.В. Косьяненко
}

кандидат юридических наук, доцент

Алтайский билиал Российской академии народного хозяйства и государственной служббы Российская Федераиия, 656008, Алтайский край, г. Барнаул, ул. Партизанская, 187

ORCID: 0000-0002-7552-9887.E-mail:gertelev@yandex.ru

\section{Ответственность за деяния, предусмотренные статьями 210 и $210^{1}$ УК РФ}

Аннотация: Статья посвящена изменениям, внесённым в уголовный кодекс РФ (УК РФ) Федеральным законом от 1 апреля 2019 г. № 46-Ф3 по ужесточению наказания за создание преступного сообщества или участие в нём. Нововведения коснулись всех частей ст. 210 УК РФ, в частности, усилилась уголовная ответственность (в основном штраф) и появилась часть 11 ст. 210 УК РФ. Кроме того, законом была введена новая статья $210^{1}$ УК РФ «Занятие высшего положения в преступной иерархии». Анализ статистики позволил выявить лишь один факт привлечения такого лица к уголовной ответственности за создание преступного сообщества. Им являлся «вор в законе», который осуществлял организационные и управленческие функции в отношении преступного сообщества и его участников. Приведённый в статье единственный по России пример свидетельствует о том, что доказать квалифицирующий признак ч. 4 ст. 210 УК РФ «лицо, занимающее высшее положение в преступной иерархии» представляет определённую сложность. Однако данных проблем не возникнет в ситуации, предусмотренной ст. $210^{1}$ УК РФ, поскольку доказывать, что такое лицо совершает деяние, не нужно. Достаточно того, что это лицо занимает высшее положение в преступной иерархии. Между тем отмеченная редакция вызывает критику, поскольку противоречит теории уголовного права в части привлечения к уголовной ответственности за совершение деяния.

Ключевые слова: преступное сообщество, ужесточение наказания, лицо, занимающее высшее положение в преступной иерархии, лидер организованного преступного сообщества, пропаганда криминального поведения.

Для иитирования: Кармановский М. С., Косьяненко Е. В. Ответственность за деяния, предусмотренные статьями 210 и $210^{1}$ УК РФ // Вестник Санкт-Петербургского университета МВД России. - 2019. - № 2 (82). - C. 147-152. DOI: 10.35750/2071-8284-2019-2-147-152.

\section{Mikhail S. Karmanovsky}

Cand. Sci. (Jurid.)

Altai institute of economy - branch of private educational institution of the higher education «St. Petersburg university of technologies of management and economy» 106-e, Lenin ave., Barnaul, Altai region, 656011, Russian Federation

ORCID: 0000-0001-8918-8334.E-mail: gertelev@yandex.ru 
Elena V. Kosyanenko

Cand. Sci. (Jurid.), Docent

Altai branch of the Russian Academy of national economy and public service 187, Partizanskaya str., Barnaul, Altai region, 656008, Russian Federation.

ORCID: 0000-0002-7552-9887.E-mail: gertelev@yandex.ru

\section{Responsibility for crimes under the articles 210 and $210^{1}$ of the Criminal Code of the Russian Federation}

Annotation: Article is devoted to the changes made to the Criminal Code of the Russian Federation by the Federal law of the Russian Federation of April 1, 2019 № 46-FZ on toughening of punishment for establishing a criminal organization or participation in it. Innovations concerned all parts of article 210, in particular criminal liability amplified (generally a penalty) and part 11 of article 210 appeared. Besides, the law entered new article $210^{1}$ of the «Occupation of the highest situation in criminal hierarchy». Having analyzed statistics, only one fact of involvement of such person to criminal liability for establishing a criminal organization is elicited. Him was «thief in law» who carried out organizational and administrative functions concerning criminal community and its participants. One example of judicial practice by part 4 of article 210 of the Criminal Code of the Russian Federation «the person taking the highest position in criminal hierarchy», proves existence of difficulties at procedural proof. However these problems will not arise in the situation provided by article $210^{1}$ as to prove that such person makes act it is not necessary. There is enough of fact that this person holds the highest position in criminal hierarchy. Meanwhile, noted edition of the law contradicts the theory of criminal law, regarding criminal prosecution only for criminal action.

Keywords: criminal community, punishment toughening, the person holding the highest position in criminal hierarchy, leader of organized criminal community, promotion of criminal behavior.

For citation: Karmanovsky M.S., Kosyanenko E.V. Responsibility for crimes under the articles 210 and $210^{1}$ of the Criminal Code of the Russian Federation // Vestnik of St. Petersburg University of the Ministry of internal Affairs of Russia. - 2019. - № 2 (82). - P. XXX-XXX.

Федеральным законом от 1 апреля 2019 г. № 46-Ф3 «О внесении изменений в Уголовный кодекс Российской Федерации и Уголовно-процессуальный кодекс Российской Федерации в части противодействия организованной преступности» ${ }^{1}$ в УК РФ введены в действие поправки, ужесточающие наказание за создание преступного сообщества или участие в нём. Как отмечается в пояснительной записке к проекту, наиболее опасные и тяжкие преступления совершаются организованными преступными сообществами. Лидеры преступных сообществ (преступных организаций) координируют преступные действия, создают

\footnotetext{
${ }^{1}$ Российская газета. - 2019. - 3 апр. - № 72.
}

устойчивые преступные связи между различными организованными группами, занимаются разделом сфер преступного влияния и преступных доходов, руководят преступными действиями и в связи с этим представляют наибольшую общественную опасность. Однако благодаря своему положению в преступной иерархии лидеры преступных сообществ (преступных организаций), как правило, уходят от уголовной ответственности ${ }^{2}$.

${ }^{2} \mathrm{O}$ внесении изменений в Уголовный кодекс Российской Федерации и Уголовно-процессуальный кодекс Российской Федерации (в части противодействия организованной преступности) : Проект № 645492-7 Федерального закона [Электронный ресурс] // Официальный сайт Государственной Думы 
Проанализировав закон, констатируем, что действующий УК РФ предусматривает в ч. 1 ст. 210 УК РФ наказание в виде лишения свободы на срок от 12 до 20 лет со штрафом в размере до 1 млн. руб. или в размере заработной платы или иного дохода осуждённого за период до 5 лет либо без такового и с ограничением свободы на срок от 1 года до 2 лет. С учётом изменений санкция статьи значительно ужесточилась в части имущественного воздействия на преступника (это не коснулось основного вида наказания - лишения свободы), в частности, размер штрафа увеличился до 5 млн. руб.

Из части первой статьи 210 УК РФ выделена в самостоятельную часть норма, касающаяся участия в собрании организаторов, руководителей (лидеров) или иных представителей преступных сообществ (преступных организаций) и (или) организованных групп в целях координации действий организованных групп, создания устойчивых связей между ними, разработки планов и создания условий для совершения преступлений, раздела сфер преступного влияния и преступных доходов между преступными сообществами (преступными организациями) и их участниками. Теперь такие действия квалифицируются по ч. 11 ст. 210 УК РФ, за них предусмотрено наказание, аналогичное тому, что ранее существовало по ч. 1 ст. 210 УК РФ, т.е. подобные действия законодатель посчитал менее опасными (альтернативно обязательное наказание в виде штрафа до 1 млн. руб. вместо 5 млн. руб., предусмотренных с учётом изменений по ч. 1 ст. 210 УК РФ). В случае, когда участник такого собрания, не успевший совершить иного преступления, добровольно выходит из преступной организации или сообщает о ней в правоохранительные органы, он, согласно примечанию к статье, освобождается от уголовной ответственности.

Что касается участия в преступном со-

Российской Федерации. Автоматизированная система обеспечения законодательной деятельности. - URL: http://asozd2c.duma.gov.ru/addwork/scans. nsf/ID/E299731789056515432583A10043867F/\$FI LE/645492-7_14022019_645492-7.PDF?OpenElement (дата обращения: 23.03.2019). обществе (ч. 2 ст. 210 УК РФ), то бывший минимальный пятилетний срок лишения свободы повысился до семи лет, а максимальный штраф - с 500 тыс. до 3 млн. руб.

Частей 3 и 4 ст. 210 УК РФ также коснулись изменения, а именно: теперь штраф в части третьей станет до 5 млн. руб. (вместо ранее предусмотренного 1 млн. руб.), а в части четвертой в виде альтернативно обязательного дополнительного наказания к срочному лишению свободы (от 15 до 20 лет) законодатель добавил штраф в размере до 5 млн. руб. или в размере заработной платы или иного дохода осуждённого за период до 5 лет либо без такового и с ограничением свободы на срок от 1 года до 2 лет. Пожизненное лишение свободы как альтернатива лишению свободы в части четвертой попрежнему сохранена.

Федеральным законом также введена в УК РФ новая статья - «Занятие высшего положения в преступной иерархии» (ст. 210 УК РФ). За такое деяние предложено наказывать лишением свободы на срок от 8 до 15 лет со штрафом в размере до 5 млн. руб. или в размере заработной платы или иного дохода осуждённого за период до 5 лет либо без такового и с ограничением свободы на срок от 1 года до 2 лет. Собственно, ради появления именно данной нормы были внесены все отмеченные выше поправки.

Кроме того, изменения внесены и в нормы Общей части УК РФ. Лицу, совершившему преступление, предусмотренное ч. 4 ст. 210 и (или) ст. $210^{1}$ УК РФ, не может быть назначено наказание ниже низшего предела или назначен более мягкий вид наказания, чем это предусмотрено данными статьями. Исключается также возможность применения условного осуждения.

Как было отмечено в законопроекте, Федеральным законом от 3 ноября 2009 г. № 245-Ф3 «О внесении изменений в Уголовный кодекс Российской Федерации и в статью 100 Уголовно-процессуального кодекса Российской Федерации» ${ }^{3}$ впервые введено понятие и установлена уголовная ответственность лица, занимающего выс-

${ }^{3}$ Собрание законодательства РФ. - 2009. - № 45. - Ст. 5263. 
шее положение в преступной иерархии, но только в случае, если указанное лицо совершает общественно опасное деяние, предусмотренное ч. 1 ст. 210 УК РФ. При этом уголовная ответственность за сам факт лидерства такого лица в преступной иерархии не предусмотрена. Сейчас же ст. $210^{1}$ УК РФ позволит привлекать к уголовной ответственности лишь за сам факт занятия высшего положения в преступной иерархии.

По поводу указанных нововведений уже высказалось ряд практиков. Так, Алексей Добрынин, партнёр коллегии адвокатов Pen \& Paper отмечает, что поправки упростят работу правоохранительным органам. «Следствию очень сложно доказать факт создания преступного сообщества. Именно поэтому проще установить, что обвиняемый занимает "высшее положение в преступной иерархии”, а для этого достаточно показаний нескольких свидетелей или, ещё проще, показаний, данных в рамках сделки со следствием, когда их достоверность не подвергается сомнениям» [3].

В законодательстве придётся дополнительно прописывать определение и критерии лидерства в преступной иерархии, указал генерал МВД в отставке Владимир Ворожцов. Сейчас, по его словам, признаки лидера организованного преступного сообщества описаны только в криминологической литературе: «Это человек, который действует в организованном сообществе, объединяет его участников, привлекает к деятельности, осуществляет постановку задач и контроль за их выполнением. Под эту категорию попадают так называемые воры в законе, смотрящие и другие авторитетные представители криминальной культуры». Однако если следователь посчитает фигуранта дела лидером преступной иерархии, ему придётся чётко это обосновывать, подчеркнул генерал [3].

Доказывать лидерство в преступной иерархии будет невероятно сложно, согласен Павел Крашенинников. Однако необходимость отдельного преследования лидеров организованного преступного сообщества есть, и она связана с тем, что их деяния «влияют на общественную жизнь гораздо сильнее, чем деяния конкретных исполнителей», - убеждён депутат [3].

Не вдаваясь в полемику о возможности / сложностях привлечения к уголовной ответственности таких лиц, заметим, что предметом уголовного права наряду с иными отношениями являются общественные отношения, возникающие в связи с совершением преступлений $[10$, с. 4]. Само же понятие преступления в социальном плане представляет собой или определенного рода поведение, или деятельность лица. В ст. $210^{1}$ УК РФ диспозиция изложена как занятие высшего положения в преступной иерархии, т.е. по сути, речь идёт не о том, что такое лицо совершает деяние, а о том, что сам факт занятия высшего положения влечёт уголовную ответственность. Указанная ситуация идет вразрез со всей теорией уголовного права. Признаки субъекта, безусловно, несут под собой негативную составляющую и очень часто дифференцируются в УК РФ (ч. 3 ст. 160 - присвоение или растрата, совершённые лицом с использованием своего служебного положения; ч. 3, 4 ст. 210 - организация преступного сообщества лицом с использованием служебного положения, лицом, занимающим высшее положение в преступной иерархии), однако такое разграничение всегда находится во взаимосвязи с деянием (действием или бездействием) лица.

Анаоиз статистики по ч. 4 ст. 210 УК РФ показывает, что за весь период существования этой части статьи был лишь один факт осуждения ${ }^{4}$. К уголовной ответственности был привлечён М.А. Чкадуа, который являлся «вором в законе» и имел прозвище «Мамука Гальский». Как было отмечено в приговоре, лицо, являющееся «вором в законе», занимает высшее положение в преступной иерархии, обладает непререкаемым авторитетом в криминальном мире, в связи с чем все лица, придерживающиеся принятых в криминальной среде правил и

${ }^{4}$ Апелляционное определение Верховного Суда РФ от 29 мая 2018 г. по делу № 51-АПУ18-4. 
традиций, должны слушать его и выполнять его указания, в противном случае, «вор в законе» может наказать неподчинившегося, и тот потеряет своей криминальный статус в преступной среде. «Вор в законе» пропагандирует «воровские идеи», сплачивает под этими идеями лиц криминальной направленности, организовывает пополнение «воровского общака», назначает «положенца», который является его ставленником и исполняет его функции и обязанности в отсутствие самого «вора в законе». «Положенец» имеет право назначать «смотрящих» за территориями, которые ему подчиняются, принимать решения по некоторым вопросам, однако решения, затрагивающие судьбу других лиц, он должен решать, посоветовавшись с «вором в законе» ${ }^{5}$.

В апелляционной жалобе по указанному приговору М.А. Чкадуа выразил несогласие с осуждением его по ч. 4 ст. 210 УК РФ, указав, что ставится знак равенства между уголовной средой, криминальным миром и преступной иерархией ${ }^{6}$. Его адвокат также указал, что, признавая М.А. Чкадуа виновным в руководстве преступным сообществом, суд исходил из сведений о том, что подсудимый, являясь «вором в законе», назначил Хаматова «положенцем» в Алтайском крае, поддерживал с ним связь по телефону, обсуждал различные вопросы, в частности, о назначении «смотрящих» в различных городах края и другие, касающиеся неформальной среды обстоятельства. По сути, именно в этих действиях, по мнению суда, выразилось осуществление функций руководителя преступным сообществом. Данное решение суда ошибочно и противоречит нормам уголовного права. По общепринятым понятиям, «вор в законе», «положенец», «смотрящий» являются авторитетами в уголовной, тюремной среде, что не предусматривает обязательного совершения ими преступлений. В частности, их дея-

${ }^{5}$ Приговор Алтайского краевого суда от 26 апреля 2017 г. по делу № 2-1/2017.

${ }^{6}$ Апелляционное определение Верховного Суда РФ от 29 мая 2018 г. по делу № 51-АПУ18-4. тельностью может охватываться контроль за местами лишения свободы, снабжение заключённых продуктовыми передачами и другие, не связанные с преступными деяниями, мероприятия. Носители указанных «титулов» не могут считаться совершившими преступление лишь в силу их уголовного «статуса», пока не совершат преступление. Назначение «воров в законе», «положенцев», «смотрящих", равно как и принятие на себя таких обязанностей уголовно наказуемыми не являются 7

Перечисленные доводы осуждённого и его адвоката судом были опровергнуты, и отмечено, что Чкадуа, будучи «вором в законе», осуществлял организационные и управленческие функции в отношении преступного сообщества и его участников; подбор и вербовку руководителей, входящих в его состав структурных подразделений, а также контроль за их действиями; планирование и координацию деятельности преступной организации ${ }^{8}$.

Приведённый нами пример, а также факт того, что он является единственным по России, свидетельствует, что доказать квалифицирующий признак ч. 4 ст. 210 УК РФ «лицо, занимающее высшее положение в преступной иерархии» представляет определённую сложность. Однако данных проблем не возникнет в ситуации, предусмотренной ст. $210^{1}$ УК РФ, поскольку доказывать, что такое лицо совершает деяние, не нужно. Достаточно того, что это лицо занимает высшее положение в преступной иерархии.

Таким образом, рассматриваемые нами изменения в современных условиях, безусловно, представляют определённую актуальность, особенно в части ужесточения наказания. Однако появление ст. $210^{1}$ УК РФ в той редакции, в которой она ныне существует, вызывает критику, поскольку противоречит теории уголовного права в части привлечения к уголовной ответственности за совершение деяния.

${ }^{7}$ Апелляционное определение Верховного Суда РФ от 29 мая 2018 г. по делу № 51-АПУ18-4. - Л. д. 74.

${ }^{8}$ Апелляционное определение Верховного Суда РФ от 29 мая 2018 г. по делу № 51-АПУ18-4. Л. д. 90. 


\section{Список литературы}

1. Белоус В. Г., Шарапова К. Г. О признаках влияния, оказываемого лидером преступного сообщества на участников организованных групп: теория и практика // Вестник международного Института управления. - 2017. - № 2 (144). - С. 10-14.

2. Белоиерковский С. Д. Новый федеральный закон об усилении борьбы с преступными сообществами: комментарий и проблемы применения // Уголовное право. - 2010. - № 2. - С. 9-14.

3. Воров впишут в закон: как Путин предложил преследовать лидеров ОПС [Электронный ресурс] // Деловой портал «РБК». - 2019. - 14 фев. - URL: https://www.rbc.ru/society/14/ 02/2019/5с6573009a79473e8a72e2a3 (дата обращения: 14.03.2019).

4. Воронин С. Э., Воронина Е. С., Железняков А. М. Организация преступного сообщества: уголовно-правовые и криминалистические аспекты : монография. - Красноярск: НОУ ВПО СИБУП, 2015. - 333 с.

5. Королёв А. С. Некоторые вопросы объективной стороны состава преступления, предусмотренного ст. 210 УК РФ // Российский следователь. - 2011. - № 10. - С. 14-18.

6. Мацаев А. М. Противодействие преступным сообществам (преступным организациям): международно-правовой аспект // Евразийский научный журнал. - 2017. - № 11. - С. 100.

7. Мондохонов А. Н. Особенности уголовно-правового статуса лица, занимающего высшее положение в преступной иерархии // Вестник Бурятского государственного университета. - 2013. - № 2. - С. 182-184.

8. Мондохонов А. Н. Вопросы уголовной ответственности за организацию преступного сообщества (преступной организации) // Уголовное право. - 2010. - № 2. - С. 51-56.

9. Петров С. В. Проблемы законодательного обеспечения борьбы с преступными сообществами на современном этапе // Юридическая наука и практика. - 2010. - № 2 (13). - С. 233-236.

10. Уголовное право Российской Федерации. Общая часть / под ред. В.В. Векленко; 3-е изд., перераб. и доп. - Омск: Омская академия МВД России, 2016. - 448 с.

\section{References}

1. Belous V. G., Sharapova K. G. O priznakakh vliyaniya, okazyvayemogo liderom prestupnogo soobshchestva na uchastnikov organizovannykh grupp: teoriya i praktika // Vestnik mezhdunarodnogo Instituta upravleniya. - 2017. - № 2 (144). - S. 10-14.

2. Belotserkovskiy S. D. Novyy federal'nyy zakon ob usilenii bor'by s prestupnymi soobshchestvami: kommentariy i problemy primeneniya // Ugolovnoye pravo. - 2010. - № 2. - S. 9-14.

3. Vorov vpishut v zakon: kak Putin predlozhil presledovat' liderov OPS [Elektronnyy resurs] // Delovoy portal «RBK». - 2019. - 14 fev. - URL: https://www.rbc.ru/society/14/02/2019/5c65730 09a79473e8a72e2a3 (data obrashcheniya: 14.03.2019).

4. Voronin S. E., Voronina Ye. S., Zheleznyakov A. M. Organizatsiya prestupnogo soobshchestva: ugolovno-pravovyye i kriminalisticheskiye aspekty : monografiya. - Krasnoyarsk: NOU VPO SIBUP, 2015. - $333 \mathrm{~s}$.

5. Korolev A. S. Nekotoryye voprosy ob»yektivnoy storony sostava prestupleniya, predusmotrennogo st. 210 UK RF // Rossiyskiy sledovatel'. - 2011. - № 10. - S. 14-18.

6. Matsayev A. M. Protivodeystviye prestupnym soobshchestvam (prestupnym organizatsiyam): mezhdunarodno-pravovoy aspekt // Yevraziyskiy nauchnyy zhurnal. - 2017. - № 11. - S. 100.

7. Mondokhonov A. N. Osobennosti ugolovno-pravovogo statusa litsa, zanimayushchego vyssheye polozheniye v prestupnoy iyerarkhii // Vestnik Buryatskogo gosudarstvennogo universiteta. - 2013. - № 2. - S. 182-184.

8. Mondokhonov A. N. Voprosy ugolovnoy otvetstvennosti za organizatsiyu prestupnogo soobshchestva (prestupnoy organizatsii) // Ugolovnoye pravo. - 2010. - № 2. - S. 51-56.

9. Petrov S. V. Problemy zakonodatel'nogo obespecheniya bor'by s prestupnymi soobshchestvami na sovremennom etape // Yuridicheskaya nauka i praktika. - 2010. - № 2 (13). - S. 233-236.

10. Ugolovnoye pravo Rossiyskoy Federatsii. Obshchaya chast' / pod red. V.V. Veklenko; 3-ye izd., pererab. i dop. - Omsk, 2016. - 448 s.

() Кармановский М.С., Косьяненко Е.В., 2019

Статья поступила в редакцию 08.05.2019. 